\title{
www.bioinformation.net
}

\section{MetaHuman genomics}

\author{
Martin Gollery ${ }^{1, *}$ \\ ${ }^{1}$ Center for Bioinformatics, University of Nevada at Reno, Department of Biochemistry, MS330, USA; \\ Martin Gollery* - E-mail: marty.gollery@gmail.com; Phone: 775784 7042; * Corresponding author \\ received January 17, 2008; published online January 27, 2008
}

\section{Editorial Message:}

Imagine for a moment that you are working on a highly visible and well funded project to study metagenomics system. After a good deal of hard work, and many reads, you study some $10 \%$ of the cell types, and identify $1 \%$ of the genes in the system. Naturally, you hold a press conference and proclaim your work to be complete.

The above scenario would seem absurd, but future generations may find that it represents the history of the Human Genome Project. While the fanfare and attention that has been heaped upon the assembly of the Human Genome has been exciting, it is not entirely well-placed. The job is nowhere near finished, for one simple reason- we are not entirely human.

I do not mean that we are alien, or somehow possessed! I simply mean that most of the cells within our bodies are non-human in origin. Fungi, bacteria and even archaea make up the majority of cells- as much as $90 \%$ by some estimates. Human cells, on the other hand, with barely over 200 different cell types, are in the minority in terms of type and number.

In addition, the total number of genes present in the body is estimated to be as much as $99 \%$ non-human. The implications of this fact are astonishing- the quality of our lives is as dependent upon the natural flora that we carry as it is upon 'our' genes. The time has come to stop ignoring the idea that humans are actually metagenomic systems. Sadly, the metagenomes of the oceans and even Pompeii worms are better studied than the one existing in our own bodies.

Fortunately, the situation is changing and is about to change even more. Jeffrey Gordon has demonstrated a significant difference in the microbial communities between lean and obese people. But this is just a taste of what is to come. The Human Microbiome Project (HMP) has recently been announced, with funding beginning later in 2008. Studying the Metagenomes of five locations in the human body will be a good start to understanding the importance of the nonhuman elements in human health and development.

Still, the HMP does not go far enough. Now we are finding that even the human cells in our bodies are not all our own. Recent studies indicate that most, if not all, people carry cells from others in a phenomena called microchimerism. Women carry cells of their children, (causing some confusion when Y chromosomes show up in tests), and many people carry cells from their mother, even late in life. Truly, the lack of understanding of the complex interplay.

What will this all mean to the working Bioinformatician? Firstly, interaction networks are going to be radically revised, as they currently are likely to be missing many important components. How can we incorporate the type and quantity of our microbial proteins into calculations when we don't know the absolute amounts of the organisms that produce those proteins in a given tissue?

Secondly, we will have to rethink our microarray designs. Probes are designed so that there is little cross talk between different mRNAs, in order to keep each probe as specific as possible. But now we can see that some of the mRNA in our sample might not come from transcription of human genes, and may interact with microarray probes, throwing off the signals.

Thirdly, we must consider non-human sources as possible causes of off-target effects in siRNA tests. A failure to account for non-human transcripts may account for inefficient and incomplete silencing of genes, and the incorporation of these transcripts into the design of the siRNAs will increase the predictability of this important tool.

What will make this so much more difficult than the average metagenome project is the shift in thinking that is required that is, first we have to convince people that this is a metagenomic system in the first place. This is a problem that other metagenomics studies, such as Craig Venter's Global Ocean Survey or the Global Viral Metagenome project have not had to struggle with. The human genome is only a part of the overall story of human biology. Until we develop a picture of the interactions of all the genes from the human and microbial genomes, that is, the MetaHuman Genome, we will not be able to completely understand the nature of human health.

Editorial: M. Gollery

Citation: Gollery, Bioinformation 2(6): 245 (2007)

License statement: This is an open-access article, which permits unrestricted use, distribution, and reproduction in any medium, for non-commercial purposes, provided the original author and source are credited. 